\title{
Electrodeposition of Gold Nanoparticles on Electrochemically Reduced Graphene Oxide for Sensitive Hydrazine Electrochemical Determination in Agriculture Wastewater
}

\author{
Xiaohui Lu ${ }^{1, *}$, Peifang Wang $^{1}$, Xianguo Wang ${ }^{3}$ and Yongbin Guo ${ }^{4}$ \\ ${ }^{1}$ School of Earth science and engineering,Ministry of Education Key Laboratory of Integrated \\ Regulation and Resource Development on Shallow Lakes, Hohai University, Nanjing, Jiangshu, \\ 210098, China. \\ ${ }^{2}$ Ministry of Education Key Laboratory of Integrated Regulation and Resource Development on \\ Shallow Lakes, Hohai University, Nanjing, Jiangshu, 210098, China \\ ${ }^{3}$ Henan Provincial Bureau of Geology and mineral resources, Jinshui Road 28, Zhengzhou, 450012, \\ China \\ ${ }^{4}$ Nanjing Hydraulic Research Institute, 223 Guangzhou Road, Nanjing, 210029, China. \\ *E-mail: luxiaohui945@hhu.edu.cn
}

doi: $10.20964 / 2016.06 .94$

Received: 25 December 2015 / Accepted: 7 January 2016 / Published: 4 May 2016

In this contribution, reduced graphene oxide-gold nanoparticles nanocomposite (RGO-AuNPs) was prepared by electrochemical reduction of graphene oxide (GO) at an indium tin oxide (ITO) electrode followed by an electrodeposition process of loading AuNPs on its surface. The electrochemical reduction and deposition progress were characterized by various techniques including SEM, XRD, UV-vis spectroscopy and Raman spectroscopy. As-prepared RGO-AuNPs modified ITO was then successfully applied for electrochemical determination of hydrazine. Results indicate that the RGO is a perfect platform for AuNPs deposition. The composite material exhibits a superior electrocatalytic property towards detection of hydrazine. Moreover, the proposed sensor was successfully used for real water sample analysis.

Keywords: Graphene; Gold nanoparticle; Electrochemical; Electrodeposition; Hydrazine

\section{$\underline{\text { FULL TEXT }}$}

(C) 2016 The Authors. Published by ESG (www.electrochemsci.org). This article is an open access article distributed under the terms and conditions of the Creative Commons Attribution license (http://creativecommons.org/licenses/by/4.0/). 